\title{
DIGITIZATION OF THE ECONOMY - REPORTING TO THE TOURISM INDUSTRY: THE GENERAL FRAMEWORK OF REGULATION, PROJECTIONS AND THE CURRENT SITUATION
}

\section{Miruna Diana MOZA}

PhD Field: Business Administration, Doctoral School of Economics, University of Oradea, Oradea, Romania

moza.miruna@gmail.com

\begin{abstract}
The way people carry out their daily activities has changed with digitalization. The digitalization process has highlighted its own effects on the economy as well as on society. Also, the way people travel has changed in terms of digitalization. Opportunities offered by this digitization process bring significant potential benefits. Thus, this paper proposes to make a brief foray and analyze the official documents that speak, plan and design the digital economy, which provides a set of projections of the digitalization of the economy, especially in the field of tourism. The analysis will be theoretical. In addition, this paper aims to give a brief overview of the current framework of the digital economy and to provide an analysis of the degree of involvement of public authorities at national level in the digitization of tourism in European countries and the number of online bookings in the same countries.
\end{abstract}

Keywords: economy, digitization, digital economy, official documents, projections

JEL classification: $A 19, D 83,033$,

\section{Introduction. Brief history of the "new economy" - the digital economy.}

Named in the literature and in the specialized field as a "new economy", the digital economy requires the use of information technology, in order to achieve the main business processes, namely planning, management and marketing. (R. Kling, $R$. Lamp, 2002). The concept of "digital economy" was first mentioned in Japan during the 1990 recession. The concept was later mentioned 5 years later in Don Tapscott's book The Digital Economy: Promise and Danger in the Age of Networked Intelligence. (1995). This is the first paper that talks about how digital networks will influence the business environment.

The impact of digitalization on the economy has become an area intensively researched by economic analysis offices and other agencies, so the Administration for Economics and Statistics has been reporting on the results of the digital economy since 1998. Over time the digitalization of the economy has received new valences and gave rise to new concepts and topics of general interes.The first interventions of the European Commission in the field of digitization were made in 2000. The European Union institutions understand at that time the importance of the Internet and technologies in the business environment and thus, "digital law" becomes one of the ten priorities of the year 2000. 
Digital transformation has become the engine of business in various fields. An area of interest was also the tourism sector. Within it, digitalization has boosted competitiveness. To this end, the European Commission has implemented a number of actions with a view to integrating companies operating in this sector into global digital value chains. At the same time, the improvement of the capacity to create more jobs was considered.

In 2010, the European Commission launches the "Digital Agenda for Europe". This was the first of seven initiatives in the Europe 2020 Strategy for Sustainable Growth. This agenda was the successor to the ICT strategy "i2010" of the European Commission 2005-2008. That agenda proposed a much wider scope. Its aim was to stimulate the European economy by providing sustainable economic and social benefits. Its areas of action included: creating a digital single market, exchanging information and setting standards, trust and security, fast and ultra-fast internet access, research and innovation, improving literacy and digital inclusion, the benefits of ICT to society, other international aspects of the digital agenda. (European Commission, 2010)

\section{The current situation of official documents, programs, projects and projections of the digitalization of the economy}

Since 2000, the European Commission has shown a growing interest in digitizing the economy. Tourism has always been an area of interest. Why is this happening? Data provided by the European Union show that in 2018, the tourism industry provided jobs to $11.7 \%$ of Europe's population. It is of great economic importance, representing at the same time $10 \%$ of the G.D.P of the European Union. This is precisely why all the commissions of the European Union are of great interest in this field. (European Parliament, 2021)

The OECD has also constantly analyzed developments in the digitalisation of the economy, progress and opportunities for the future. All these reports, programs and guidelines have been summarized in this chapter.

\subsection{General aspects and reflections in the tourism sector}

One of the new concepts launched with the Digital Agenda for Europe was the "digital single market", which later became a 2015 strategy that included a series of initiatives to remove barriers to cross-border e-commerce and stimulate investment in T.I.C. Thus, the DSM (Digital Single Market) strategy represented for the period 2014-2020 a point of great interest, being based on 3 main pillars, namely: facilitating the access of consumers and businesses to digital goods and services, throughout Europe, creating the right conditions and for digital networks to grow and maximize the growth potential of the digital economy (European Commission, 2015)

In the context of the Digital Single Market, the European Commission has also turned its support to the tourism industry, establishing four sets of initiatives:

Improving the business environment and increasing investment in the tourism sector, through better use of EU funding

Stimulating digitalization in this industry and the use of online marketing tools Improving the skills and competencies of this sector in order to improve career prospects and identify and retain professionals in the field 
Raising Europe's profile as a tourist destination, complementing promotion efforts at regional and national level in order to attract a greater tourist flow in Europe.

Following a political agreement between the European Commission, the European Council and the European Parliament, the N.I.S (Network and information Security) Directive (European Commission, 2015) on network and information security was adopted in 2015 . This has played a key role in what we call the digitalization of the economy. In 2016, the directives on the general regime for the protection of personal data are repealed (European Commission, 2015).

However, the first step taken by the European Commission towards what we call digital tourism and the digitalisation of this sector was launched in 2015. The socalled "Digital Tourism Network" was an informal forum for the tourism industry in the European Union / Its purpose was to facilitate discussions on the common challenges and opportunities that the digital transformation brings to the tourism industry. Moreover, the forum also served as a facilitator of the exchange of good practices and of stimulating the innovation capacity of tourism enterprises (especially SMEs). This network subsequently contributes to the formation of new actions that will aim to support the digital development of the industry. Thus, in 2016, the European Commission conducts a consultation in this regard and publishes two reports on the digitization of tourism.

The OECD (2015) presents in the OECD Digital Economy Outlook 2015 report the possibilities of capitalizing on the potential of the digital economy as an engine for innovation of countries, targeting numerous sectors of activity and industries. It sets out the current state and prospects of the digital economy, the main trends in the ICT sector and the effects of the digital economy on growth and development in various industries, including the tourism industry. According to the report, the potential for companies to adopt and use the Internet and digitalisation in all sectors is huge, and O.E.C.D. governments are increasingly aware of the need to develop the digital economy. The aim is to stimulate economic and social growth through national digital agendas. (O.E.C.D, 2015)

At the same time, in 2015, the United Nations launches the post-2015 development agenda. It sets out a number of sustainable development goals, including internet access to create an inclusive and global digital economy.

The 2017 O.E.C.D Digital Economy Outlook report highlights a number of key ideas: O.E.C.D governments meet the challenges of digital transformation in all branches of the economy; communication infrastructure and services are being modernized; the use of T.I.C is unequally distributed between countries, between companies and between individuals; digital innovation and digital transformation bring important changes to the labor market; concerns about digital security and privacy limit the widespread adoption of T.I.C and business opportunities; artificial intelligence raises a number of political and ethical questions; the potential of the blockchain faces a number of technical obstacles and political challenges. (O.E.C.D, 2017). Also in 2017, the European Commission launches the report "Management and Content Provision for ICT and Tourism Business Support Portal". The project aims to increase the competitiveness of tourism businesses using ICT. According to him, SMEs in this industry will be supported to acquire and adopt the necessary technologies and skills. The report sets out, for each EU member state: the level of digitization, the way data is processed, the attitude towards digitization and the existing challenges. (European Commission, 2017) 
In 2018, the final report "Digitalization in tourism" is published. Their aim was to analyze the challenges and opportunities of digitalisation in tourism, how these challenges and opportunities affect different stakeholder groups and to discuss how they could be addressed. It was found that there are five major needs in terms of the activity of tourism SMEs, namely: skills, funding, infrastructure, mentoring and political support. Moreover, the recommendations offered were summarized as follows: continuous consultation in the chain of SMEs-public authorities, professional associations, technical assistance in the form of digital training courses, promotion of infrastructure in rural areas and beyond. However, their implementation requires collaboration with other complementary industries.

The year 2020 brings to the fore a new report provided by the OECD, named Digital Economy Outlook 2020. The current pandemic of COVID-19 has amplified all aspects of digital transformation and the way countries interact with digital technology. At the same time, it highlighted the need for a more inclusive approach to digital transformation.

OECD countries are strengthening their strategic approach to digital transformation policy, so by mid-2020, 24 OECD countries had a national strategy aimed at digitizing the economy. The report also highlights the implementation and the effects of the digital divide. There are major differences between large firms and small firms. If for large companies, e-commerce represented in $2019,24 \%$ of turnover, for small companies, the share represented was $10 \%$. Such gaps also exist among individuals, the differences in use by age groups and level of education persisting to date.

The measurement of the progress in which the member states of the European Union act in the direction of a digital economy is made through D.E.S.I. indicator (Digital Economy and Society Index). This indicator refers to five major areas, namely: connectivity, human capital, internet use, digital technology integration and digital public services. (I.N.S, 2020)

The data provided by this index reveals the current situation of Romania in this context, thus, in terms of connectivity, there is an upward trend 2014-2017 and a maintenance trend with small decreasing influences in the period 2017-2019. In the field of internet services use, the digital environment shows an accelerated growth, so in $2019,71.6 \%$ of people used the internet regularly, an increase of $23.9 \%$ compared to 2014. Moreover, a significant increase it was also found among online transactions. Digital technology in enterprises is also presented in the report. According to him, the digital sphere provided $7.4 \%$ of turnover, $10.3 \%$ of enterprises bought cloud services, which is implicitly a trend of digitalization in enterprises and SMEs receive more and more digital orders and the share of companies who used social networks in 2019 was $33.2 \%$.

At the level of the European Union, this indicator shows similar trends and an upward trend. Internet use has increased year by year, with $85 \%$ of Europeans using the internet at least once a week. At the EU level, the purchase of cloud services accounts for much higher percentages from companies, namely $38.5 \%$. General connectivity and digitalization of households have improved significantly, and human capital has also increased in the context of the skills of internet users. (I.N.S, 2020)

Connectivity is also continuing to improve in OECD countries, communications subscriptions are growing sharply and policy and regulatory measures are being put in place to manage them as efficiently as possible and to facilitate the 
implementation of access to these facilities. The report also highlights the implementation and the effects of the digital divide. There are major differences between large firms and small firms. For large companies, e-commerce in 2019 accounted for $24 \%$ of turnover. For small companies, it accounted for only $10 \%$ of turnover. Such gaps also exist among individuals, the differences in use by age groups and level of education persisting to date.

Big data also offers more and more opportunities for companies and consumers. However, security and confidentiality issues arise in this context. The report highlights the added importance of OECD countries' efforts to identify policy solutions to digital security issues and to stimulate good practice. (O.E.C.D, 2020)

\subsection{Harmonization of digital markets - as a central objective}

The harmonization of digital markets has remained one of the clear objectives of the European Commission. Over time, this goal has also been one of the key policies through which the EU supports its Eastern European partners. To this end, the project called EU4DIGITAL was born. It aims to expand the Digital Single Market to Eastern partners, contributing to economic growth, creating new jobs, improving people's lives and supporting the business environment.

In this context, the EU supports the reduction of roaming charges, the creation of a high-speed broadband network which in turn will contribute to the growth of the economy, the expansion of online services and a coordinated and organized cyber security. These measures help to remove barriers to online services for citizens, administration and business. Under these conditions it will be easier to attract investment, sales will increase, and launching and developing a Start-up will be much easier.

The EU4DIGITAL initiative brings together the following actions and programs:

- EU4DIGITAL networks - bringing together EU representatives and Eastern partners to work on key issues,

- EU4DIGITAL facility - a 3-year program (2019-2022) that promotes the highlights of the digital economy in line with EU rules and practices,

- EU4DIGITAL broadband strategies - (2018-2020) is a World Bank project that supports Eastern countries in creating national strategies for highspeed data networks

- EU4DIGITAL Cybersecurity East - a project that aims to strengthen cybersecurity and increase trust in the use of online services.

- EU4DIGITAL EaPConnect - expanding the digital infrastructure to bring together scientific studies and education

The European Investment Bank also talks about Digitalisation in Europe 20202021 in the "Digitalisation in Europe 2020-2021" Report. It is a balance of evolution. This balance sheet sets out the pace of adaptation of digital technologies and, implicitly, their impact in both the European Union and the United States. The report highlights a number of issues specific to the digitalisation of the economy.

In the first instance, in order to achieve sustainable growth, Europe must embrace and tap into the potential of digital technology. The digital revolution has already transformed the economy, although many of these changes have only just begun. Asked by the European Investment Bank, a significant percentage of EU companies believe that this process of business digitalization has been accelerated by the COVID-19 pandemic. 
Another trend mentioned in the report is the importance of adopting digital technology in order to remain competitive in the market. Moreover, although the adoption of digital technologies by European businesses is growing, this growth is not enough to reach the level of those in the U.S.A.

Very large discrepancies between countries are also mentioned in this report. While some EU member states are at the forefront of global digitalisation, others are failing to keep up with this development. The data show that digitized companies are much more productive, so according to the report, digitization is an opportunity and not a risk.

A measure mentioned in the report of the European Investment Bank aims to identify and solve the problems that hinder the evolution of digitalization. Thus, in order to accelerate innovation and the adoption of digitalisation, Europe must take into account the three key issues: a functioning and permissive system, sound financial support for investment and a European vision to combat imbalances within the European Union.

In this context, in order to boost the development of this sector, the EU has launched the Digital Europe Program, which provides funding focused on the digitalisation of businesses, public administrations and citizens. Digital technology and infrastructure play a key role in our private lives as well as in the business environment. We rely on this activity to communicate, work, learn and innovate. At the same time, the COVID-19 pandemic highlighted not only how much we rely on the availability of technology but also how important it is not to rely on systems and services from external sources, thus paving the way to achieve this goal, a digital Europe, independent and efficient.

The program provides funding and strategic support in 5 key areas: supercomputing (high data processing power); Al (Artificial Intelligence) - Al (Artificial Intelligence); Cybersecurity; Advanced digital knowledge (among the population); The widespread use of digital technologies in business and society. This program has 7.5 trillion Euros, complementing the rest of the existing programs and is part of a long-term strategy, called the Multiannual Financial Framework 2021 - 2027. (European Commission, 2021).

At the same time, the Connecting Europe Facility (C.E.F DIGITAL) program focuses on the development of digital infrastructure in the transport, telecommunications and energy sectors, all of which have clear influences in the field of tourism. Some important issues are: the development and wider coverage of high-capacity networks, including 5G; increase the security, resilience and capacity of the main EU networks, boost the digitalisation of energy and transport networks.

C.E.F DIGITAL aims to finance the installation of $5 \mathrm{G}$ systems along the main transport routes, highways, ports and railways, which will pave the way for new innovative services, through artificial intelligence, both for the population and for the transport of goods. At the same time, these projects will give rise to "smart communities", with applicability in schools, public institutions, hospitals, etc.

For the same purpose, it is desired to extend quality networks in isolated areas (islands or rural areas), but also of submarine cables that will ensure connectivity between Member States and other partners. (European Commission, 2021)

The OECD report on "Digitization: policy-making, improving lives" also highlighted the need to close the gaps that exist in order to address the opportunities of the digital age. It was therefore considered that a deeper understanding of the need for 
these changes is imperative and affects the whole economy and society. (O.E.C.D, 2019)

Referring to digitalisation and sustainability, in 2021 the European Economic and Social Committee launched an exploratory opinion setting out a series of recommendations, proposals and requests as follows:

Call for policies to establish a digital economy, enabling workers, consumers, SMEs, large companies and non-profit economic operators to benefit equally, especially in rural areas. These policies included issues such as: developing fiscal policies to ensure that digital companies pay their tax contributions, adjusting competition and monopoly legislation, using R.G.P.D for social media and ecommerce platforms

Demand for transparent, fair and environmentally friendly ICT production chains, ambitious energy standards and an extension of the EU Ecodesign Directive

Call for appropriate policy measures to help strengthen practices such as: increased use of ICTs that have mitigated energy-intensive work practices and lifestyles as a result of the pandemic

Recognize the key importance of developing sustainable smart cities, including innovative approaches to integrated mobility, energy and tourism. (European Economic and Social Committee, 2021)

In the tourism industry, the promotion of digital transformation has continued through many types of activities: the existence of a tourism business portal, including various articles and tools useful to entrepreneurs on managing the tourism business in the digital age, webinars and local workshops in 5 major cities in Europe.

Following the public consultation and analysis of the current context, the European Union has launched a renewed policy initiative to support the sustainable adaptation of EU Member States' education and training systems in the digital age, implementing an Action Plan for Digital Education (2021- 2027). This plan does not directly target the digitalization of the economy but indirectly supports this process. $\mathrm{He}$ has a long-term vision of increasing the quality and accessibility of high-level education. (Digital Education within the Directorate-General for Education, Youth, Sport and Culture, 2021).

Numerous operational programs and solutions for organizing and supporting the process of digitization of the economy have emerged at the level of all EU member states. Ministries of the economy are increasingly promoting digital services in the business environment.

\section{Involvement of public administrations at national level in the field of tourism. Analysis and effects.}

The methodology used for this study consisted in the analysis of literature, official documents, previous and current research and official reports, which focus on the field of digitization of economic sectors and especially tourism.

The methodology used for this study consisted of the analysis of specialized literature, official documents, previous and current research and official reports, which focus on the field of digitization of economic sectors, especially in tourism

The experience of developed countries has shown that information technology has an increased impact on the country's competitiveness and the opportunities they discover. The reporting and implementation of all policies imposed at European level has differed from country to country. The involvement of public 
administrations and professional associations has also been variable. The report on digitalization in tourism, of 2018 presents an important aspect in this context, namely: the involvement of public administrations and professional associations in the digitalization of business. It has previously been shown that public administrations can play an important role in developing initiatives such as funding certain programs. At the same time, their involvement was highlighted less in projects or technical elements of digitization.

The way of implementation and involvement has varied at the level of European countries. In the following, we took into account as a reference variable, the involvement of the public administration at national level. Thus, it was found that $75 \%$ of European public administrations were involved in supporting the digitization of tourism. In the top of the most active countries were the Nordic countries. The activities implemented at the level of European countries, with the help of local administrations, aimed, concretely, to carry out actions such as: gathering information, providing financial support, assistance for e-governance, while professional associations focused on educational activities, support for providing financing and marketing media such as websites, online transactions and more.

Thus, according to the Tourism Digitization Report 2018, we notice that the Nordic countries (Finland, Denmark, Sweden, the Netherlands) have the highest levels of digitalization, at the end of the list being the Eastern European countries.

In the Nordic countries, $70 \%$ of tourism SMEs have shown that they have an average level of digitalization, while in Eastern European countries there is a percentage of $44 \%$.

An example of good practice, implemented by Finland, was to create digital ecosystems at national level and to make tourism services available on as many digital channels as possible both nationally and globally. Thus, pilot projects were carried out, focused on the digital experience of tourists in four areas. It has contributed to the personalized development of digital know-how and services, subsequently, a national hub has been implemented and e-learning and digital training activities for tourism. For the future, a digital inventory of tourism assets is being pursued. (O.E.C.D, Finland, 2021)

In parallel with this analysis, we found it useful to analyze the number of holidays booked in European Union countries, using online booking. Thus, the following information was taken from Eurostat on the number of online bookings in the countries between the two main categories mentioned above.

Table 1 Number of internet booking of the main means of accommodation in 2018

\begin{tabular}{|c|c|c|c|c|c|c|}
\hline & \multicolumn{3}{|c|}{ Nordic Countries } & \multicolumn{3}{|c|}{ Eastern Europe Countries } \\
\hline Country & $\begin{array}{l}\text { Sweede } \\
n\end{array}$ & Finland & Netherland & Albania & Montenegro & Latvia \\
\hline $\begin{array}{l}\text { Internet } \\
\text { booking } \\
\text { of the main } \\
\text { means } \\
\text { of } \\
\text { accomodat } \\
\text { ion }\end{array}$ & $\begin{array}{l}8,269,86 \\
1\end{array}$ & $\begin{array}{l}6,210,93 \\
3\end{array}$ & $5,865,395$ & 16,883 & 47,082 & 157,476 \\
\hline
\end{tabular}

Source:https://ec.europa.eu/eurostat/databrowser/view/TOUR DEM TTORG cus tom $1768446 /$ default/table?lang=en 
Therefore, as can be seen in the table above, the countries that are part of the category of Nordic countries, register values of online booking with an average of about 10 times higher than the Eastern countries.

Drawing a parallel with the previously analyzed study, regarding the active involvement of public administrations in the digitalization of tourism, we find that the effects of these positive policies are obvious. Thus, the countries in which the involvement of the public authority has increased shares (70\%), Sweden, Finland and the Netherlands, enjoy the highest values of online booking at European level, while countries in the Eastern category, where the involvement in digitization it was minimal, it records the lowest values.

This analysis presents as limits a number of aspects such as: the number of online bookings is not conditioned only by the involvement of public administrations in the digitization of tourism. Here we can involve other factors such as: major differences in terms of tourism potential of countries, differences in the economic development of the country and in terms of quality of services. Thus, this paper will be the basis for other research, which will develop this topic, analyzing in detail all the influencing factors according to which online bookings in the Nordic countries have such significant values as opposed to those in Eastern Europe. At the same time, it will be possible to provide a guide to good practice and a set of recommendations for countries in the second category.

Moreover, Eastern European states, being members of the EU, have allocated funds for digitization, but due to administrations, often inefficient, this money is either not absorbed or used inefficiently.

Thus, I believe that at the level of the European Union, it would be useful to set up a group of professionals to help raise the standards of all countries in terms of digitization. Moreover, it would be useful to carry out support activities to contribute to the development of digitization in this area.

\section{Conclusions}

The current situation in Europe reflects a conventional digital divide. Moreover, the current state of regulations is uneven. Each country approaches this issue in its own way and has influences from the great economic powers. While some countries enjoy unlimited capabilities to turn data into digital intelligence and business opportunities, which are later used for economic and social development, there are also some countries whose capabilities in this area are limited, thus speaking of a disadvantage.

Where public administrations have been involved in digitization and have done so in an appropriate way (eg the Nordic countries, Finland), the results have not been long in coming. Thus, it is easy to see from the two statistics provided (involvement of public administrations in digitization and the number of bookings made online) that in countries where we talk about implementing activities to develop digitization and the number of tourists who choose online bookings is much bigger.

A multitude of operational programs, agendas, reports, organizational solutions and individual activities of major organizations exert their influence in the field of digital development. Involved in this subject since 2000, the European Commission is continuously focusing on facilitating digitization and removing barriers. 5 years 
later, the European Commission's interest in integrating the concept into tourism appears, launching the orientation of activities towards digital tourism. The promotion of digital tourism and the digitization of tourism leaves room for many other interpretations, being the solution for many other problems encountered in this sector and at the same time, a step towards the future.

Recent years have brought new attributes to the development of digitalization. In this regard, the strengthening of the strategic approaches of OECD countries was exemplified. Thanks to the COVID-19 pandemic, by the middle of 2020, 24 of these countries already had a complex national strategy developed in this regard.

\section{References:}

1.Digital Education in the Directorate-General for Education, Youth, Sport and Culture, 2021, [Online], Available: https://ec.europa.eu/education/education-in-theeu/digital-education-action-plan ro [16.Oct.2021]

2.European Commission, (2010), A Digital Agenda for Europe, Commission Europeana, Communication from the commission to the european parliament, the council, the european economic and social committee and the committee of the regions, Brusseles

3.European Commission, (2015), A Digital Single Market Strategy for Europe, Communication from the commission to the european parliament, the council, the european economic and social committee and the committee of the regions, Brusseles

4. European Commission, (2015), Commission welcomes agreement to make EU online environment more secure, [Online], Available: http://europa.eu/rapid/pressrelease IP-15-6270 en.htm [23.Oct.2021]

5.European Commission, (2015), Aging on Commission's EU data protection reform will boost Digital Single Market, [Online], Available: https://ec.europa.eu/commission/presscorner/detail/en/IP 15 6321 [01.Nov.2021]

6. European Commission, (2017), Management and Content Provision for ICT and Tourism Business Support Portal Final Report

7.European Commission, (2018), Digitalization in Tourism, Final report

8.European Commission, (2021), The Digital Europe Program, 2021, [Online], Available: $\quad$ https://digital-strategy.ec.europa.eu/en/activities/digital-programme [02.Nov.2021]

9.European Commission, (2021), The Digital Europe Program, 2021, [Online], Available: $\quad$ https://digital-strategy.ec.europa.eu/en/activities/digital-programme [02.Nov.2021]

10.European Economic and Social Committee, (2020), Digitization and sustainability - the status quo and the need for action from the perspective of civil society, (exploratory opinion)

11.European Investment Banck, (2021), Digitalization in Europe Report: 2020-2021 12.EU4 DIGITAL, 2021, [Online], Available: https://eufordigital.eu/discover-eu/theeu4digitalinitiative [04.Nov.2021]

13.European Parlament,(2021), Tourism, [Online]. Available https://www.europarl.europa.eu/factsheets/en/sheet/126/tourism [13.Dec.2021]

14. Eurostat, (2021), Number of trips by type of organisation, Internet booking of the main accommodation, [ Online]. Available 
https://ec.europa.eu/eurostat/databrowser/view/TOUR DEM TTORG custom 17 68446/default/table?lang=en [10.Dec.2021]

15.I.N.S, (2020), Index of the digital economy and society (D.E.S.I), 2020

16.Kling, R. \& Robert, L. (2002). IT and Organizational Change in Digital Economies. Center for Economic Studies \& University of Maryland

17.OECD, (2015), Digital Economy Outlook 2015, [Online], Available: https://read.oecd-ilibrary.org/science-and-technology/oecd-digital-economyoutlook-2015 9789264232440-en\#page15 [ 05.Nov.2021]

18. OECD, (2017), Digital Economy Outlook 2017, [Online], Available: https://read.oecd-ilibrary.org/science-and-technology/oecd-digital-economyoutlook-2017 9789264276284-en\#page15 [05.Nov.2021]

20. OECD, (2019), Going Digital: Shaping Policies, Improving Lives, [Online], Available: $\quad$ https://www.oecd.org/publications/going-digital-shaping-policiesimproving-lives-9789264312012-en .htm [09.Nov.2021]

17.OECD (2020), Finland, [ Online], Available: https://www.oecdilibrary.org/sites/cb702fad-en/index.html?itemld=/content/component/cb702fad-en

[14 Dec.2021]

21. Tapscott, D., (1997) .The digital economy: promise and peril in the age of networked intelligence. New York: McGraw-Hill 